\title{
Modelling urban mixed land-use prediction using influence parameters
}

\author{
Poulomee Arun Ghosh ${ }^{1 \otimes}$ - Pratap M. Raval ${ }^{2}$ \\ ${ }^{1}$ National Institute of Construction Management and Research (NICMAR), Pune, Maharashtra, India \\ ${ }^{2}$ College of Engineering, Pune (CoEP), Maharashtra, India \\ $\bowtie$ poulomee16@gmail.com
}

\begin{abstract}
Mixed land-use is a popular concept in urban planning due to its expected role in improving environmental sustainability as well as citizen's quality of life. Land use planning and regulations are not stringent in many cities like those in India, and policies are liberal towards mixed land uses. In these cities, mixed land-uses are a natural phenomenon manifesting under various influencing parameters. However, for studies on mixed land-uses, these cities pose data insufficiency challenges, as vital comprehensive spatial information related to land-uses is not available. Moreover, there is no standardised methodology established to assess the spatial distribution of mixed land-uses at the city level. This research has developed a GIS-based model using Weighted Overlay Analysis to predict and visualise the probability of mixed land-use at the macro or city level for the case of Pune, India. The model uses the easily available spatial data of influencing parameters of mixed land-use as input for prediction instead of comprehensive real land-use data. The model is validated by comparing the predicted mixed land-use intensities with established indicators of mixed land-use for four neighbourhoods. It is found that parameters that influence mixed land-use such as connectivity, grain pattern, population density and access to amenities can be used to predict the probability of mixed land-use. Around 35 per cent of the city area of Pune has more than 0.67 probability of mixed land-use. The model can produce the probable mixed land-use distribution across the city and can be used to compute mixed land-use intensities for neighbourhoods.
\end{abstract}

Highlights for public administration, management and planning:

- Mixed land-use probability distribution for Pune City, India is generated using Weighted Overlay Analysis in GIS.

- As vital spatial data of land-use was unavailable, the prediction model uses data of influencing parameters of mixed land-uses such as population density, connectivity, grain pattern and access to amenities.

- The mixed land-use probabilities predicted can be used to compute mixed land-use intensities of neighbourhoods. It is validated by comparing with traditional mixed land-use indicators.

\section{Introduction}

Mixed land-use is propagated in many modern town planning concepts worldwide (Herndon \& Drummond 2011; Kajtazi 2007). The popularity is due to its role in achieving urban sustainability through intensive and diverse land utilisation that reduces car dependence and increases social cohesion. Mixed land-use can be defined as an integrated co-existence of more than one primary land-uses

\section{Keywords}

Mixed Land-Use

Prediction,

Influencing Parameters,

Weighted Overlay

Analysis,

Mixed Land-Use

Indicator

Received:

25 December 2020

Received in revised form:

24 May 2021

Accepted:

28 May 2021 2015; Grant 2002; Jacobs 1961; Zagorskas 2016). Owing to the complexity in which different landuses can conglomerate, mixed land-use for social studies purposes can be understood as the extent to which non-residential uses exist and integrate within the walking distances of residential use (Hirt 2007; Mott MacDonald 2014; Song et al. 2013). Therefore, mixed land-use is not an actual land-use category pointing to any particular use but is determined from the presence of other land-uses. 
Despite the popularity of mixed land-use, there is no single standardised method of measuring and visualising mixed land-uses (Song et al. 2013; Zagorskas 2016). Measurement and analysis technique of mixed land-use is subjected to geographical scale considered in a study, varying from building level to city level (Hoppenbrouwer \& Louw 2005; Rodenburg \& Nijkamp 2004). There is good knowledge present in literature regarding index computation for mixed land-uses that enumerates mixed land-use intensity or diversity of land-uses even if none are adopted as a standard way of measurement (Abdullahi et al. 2015; Bordoloi et al. 2013; Song et al. 2013). Indices are useful for comparative purposes across neighbourhoods or cities. However, there is a lack of literature that comprehensively analyses spatial mixed land-use distribution at a city level. This paper intends to contribute to this research gap by proposing a model to predict and visualise mixed land-use distribution in a city based on the influencing parameters.

The second significant contribution of this research is towards the utility of the model in the context where mixed land-use occurs naturally. Jane Jacobs envisages that cities are natural generators of mixed land-use, which not only have the required threshold population for diverse enterprises but also have diverse people with varying tastes and needs knit together (Jacobs 1961). Like the city of Pune, where urban planning and land use governance is strategic and mixed land-uses are not strictly regulated, mixed land-uses become an organically developing inherent character (Bahadure \& Kotharkar 2015; Raman \& Roy 2019; Williams 2004). Various external parameters instead of regulations such as population density, grain pattern, and connectivity influence the extent of mixed land-use development (Hoppenbrouwer \& Louw 2005; Huang \& Tsai 2013; Shi \& Yang 2015; Yinan 2009). As land-use zoning and planning are not administered in such cities, detailed land-use maps might not be available (BusinessLine 2012; Ahluwalia 2019; Moreri 2020). Past visualisation and prediction models of mixed land-use in literature almost always depended on the existing land-use data (Abdullahi et al. 2015; Huang \& Tsai 2013; Zagorskas 2016). This data insufficiency gives rise to the need for this research. Geographical Information System (GIS) based modelling with open source data form an efficient and reliable method for researches in the scenario of official data insufficiency. In India, a mixed land-use policy is now included in its Smart City Mission and the Transit-Oriented-Development (TOD) Policy that is promoted by the Ministry of Housing and Urban Af- fairs, Government of India (2016; 2017). However, given that the cities already host mixed land-uses, understanding the existing mixed land-use conditions is essential for policy formulation and implementation.

This paper explores at the macro or city level the probable spatial distribution of mixed land-use across the city of Pune based on GIS-based modelling. The model is not based on actual existing land-use distribution due to insufficient data but is predicted from the influencing parameters of mixed land-use whose data is easily and freely available in the public domain. The model is validated through mixed land-use index calculation at the micro or neighbourhood level, the method for which is well established in the literature (Song et al. 2013). How well the macro-level mixed land-use prediction model can predict the real situation is checked through the micro-level or neighbourhood study.

\section{Literature Review}

\subsection{Parameters that Influence Mixed Land-Uses}

The parameters to be considered as the influencers of mixed land-use are determined from the literature. As per Jane Jacob (1961), internal areas of a city serving more than one function, short blocks, frequent turns, the mingling of new and old buildings, and higher density are the urban conditions leading to diversity. The mixed land-use model proposed by Rowley (1996) and Hoppenbrouwer and Louw (2005) gives a precise understanding of the parameters that govern the manifestation of mixed land-uses. The models emphasise the geographical scale of consideration for the mixed land-use studies varying from building to city level. At the macro/city level, the models consider urban texture (grain, density, and permeability), location, public policy, and activities as mixed land-use influencers (Hoppenbrouwer \& Louw 2005; Rowley 1996). Influencing parameters of mixed landuses considered in the literature is not uniform, and a variety of terminologies are used. Table 1 indicates the parameters that influence mixed land-uses taken from literature and organised in the author's terms.

A flexible and supportive public policy is necessary for the manifestation of mixed land-uses (Abdullahi et al. 2015). This is the reason behind choosing Pune for the study. Density, grain and connectivity are essential attributes of city form 
Table 1 Parameters that influence mixed land-use from literature

\begin{tabular}{ll}
\hline $\begin{array}{l}\text { Parameters that influence } \\
\text { mixed land-uses }\end{array}$ & References \\
\hline Public Policy & (Hoek 2008; Hoppenbrouwer \& Louw 2005; Jacobs 1961; Rowley 1996) \\
\hline Connectivity & $\begin{array}{l}\text { (Chen 2014; Gehrke \& Clifton 2016; Hoek 2008; Hoppenbrouwer \& Louw 2005; } \\
\text { Mashhoodi \& Pont 2011; Narvaez 2015; Rowley 1996; Shi \& Yang 2015) }\end{array}$ \\
\hline Road Network/ Layout & $\begin{array}{l}\text { (Chen 2014; Gehrke \& Clifton 2016; Hoek 2008; Hoppenbrouwer \& Louw 2005; } \\
\text { Jacobs 1961; Kajtazi 2007; Mashhoodi \& Pont 2011; Narvaez 2015; Rowley 1996) }\end{array}$ \\
\hline Grain Pattern / Built Density & $\begin{array}{l}\text { (Chen 2014; Gehrke \& Clifton 2016; Hoek 2008; Hoppenbrouwer \& Louw 2005; } \\
\text { Jacobs 1961; Kajtazi 2007; Mashhoodi \& Pont 2011; Rowley 1996; Shi \& Yang 2015) }\end{array}$ \\
\hline Location & (Hoek 2008; Hoppenbrouwer \& Louw 2005; Huang \& Tsai 2013; Narvaez 2015; Rowley 1996) \\
\hline Population Density & (Hoek 2008; Huang \& Tsai 2013; Jacobs 1961; Mashhoodi \& Pont 2011; Shi \& Yang 2015) \\
\hline Access to Amenities & (Chen 2014; Hoek 2008; Hoppenbrouwer \& Louw 2005; Jacobs 1961; Kajtazi 2007; \\
\hline
\end{tabular}

(Lynch 1984), which influence mixed land-use. Narvaez (2015) has shown that mixed land-use presence reduces with distance from the Central Business District. Mixed land-uses also decreases with the reduction in street connectivity. Accessibility could be depending on the road network and layout of the neighbourhoods. Mixed-use gets generated more often in areas with high accessibility due to a higher number of visitors (Shi \& Yang, 2015). Locations reflect the age of the development, with newer areas posing larger grain size than older neighbourhoods with fine grains (Hoek 2008). A fine-grain character presents more opportunity for the development of mixed-use (Jacobs 1961). Literature has proven that higher densities generate a higher potential for functional mixeduse development (Mashhoodi \& Pont 2011; O'Sullivan 2012). Access to amenities for residents is one of the benefits of mixed land-uses, and its measurement could indicate the presence of mixed land-use. Hence, for this study, it is assumed that a certain relationship exists between mixed land-use and the influencing parameters. How these parameters are measured is discussed in the methods section.

\subsection{Past Methods of Mixed Land-Use Visualisation}

A prominent way of visualising mixed land-use is to simulate it from the existing parcel-level landuse map. One way is to compute proximities between different land-uses for all land-use categories and then to grade all pixels in a range for visualisation (Abdullahi et al. 2015). Another way is to classify the land uses into minimal categories like work, home and others, and then computing an index for sample points or neighbourhoods which may represent larger areas (Kawabe \& Watanabe 2018; Zagorskas 2016). Once a particular diversity index is computed for each land parcel, Geographically Weighted Regression can be performed with other parameters to formulate a mixed land-use prediction model (Huang \& Tsai 2013). However, as for this study, the production of detailed landuse information for the whole city was not feasible, and hence, the aforementioned processes could not be used.

Another way is to use open access geographical data like Points of Interests (POI) from Open Street Map (OSM). The POIs or polygon information from OSM can be categorised in more straightforward land-use categories and then can be used for mixed land-use index computation using any established diversity index or Kernel Density Estimation (Gervasoni et al. 2016; Yue et al. 2017). However, as much of this information is crowd-sourced, completeness of data cannot be assumed, and small business establishments and residential properties may not be mapped. Therefore, they cannot be the only basis for analysing mixed land-use in this study.

We adopted the GIS-based Weighted Overlay Analysis for this study as it manipulates spatial data organised in different layers to create combined spatial features (Raju 2003). Information regarding the various influencing parameters was not available at the same geographical scale, and also, they don't play an equal role in determining mixed landuses. In such a scenario, Weighted Overlay Analysis was found to be a suitable way of combining the information of multiple criteria to predict and visualise mixed land-use distribution at macro-level. 


\section{Study Area}

Pune City in India grew from a village in the Seventeenth Century to become a metro city where currently a population of 3.13 million reside in 331.26 square kilometres (Pune Municipal Corporation, 2020). Older parts of the city called the core area has developed before formal land-use planning started. Hence, they have an organic character with high population density as well as a high concentration of commerce (Diddee \& Gupta 2013). Buildings are of low-rise traditional character with high ground coverage, back to back structures, low margins and extensive vertical mixed-use (multiple uses within a building) with shops on the ground floor and multi-family residential blocks above. Redeveloped buildings in this area follow a similar character, except that they may be mid-rise.

For the rest of the city, development has occurred under the strategic 20 years 'development plan' and the associated 'controls regulations' (Pune Municipal Corporation 2018). The development control regulations encourage the natural mixing of landuses. It does not follow a zoning-land-use matrix type of management, but instead, broad landuse zones are indicated in the development plan for each land parcels based on adjoining road width. Land-use zones are indicative of the prominent use only, and many other uses are permitted depending on the adjoining road width. For instance, even if a plot is indicated as residential use, it could be in reality commercial or office space or recreational. Whether a particular use requires a separate building or can be a part of combined use is specified. Residential use is encouraged in business districts as well, and there is no clustering of non-residential uses. There is no compulsion of mix-use or no separate mix-use zone as there is support for mixing uses in all parts of the city. Moreover, there is no limits on plot sizes, no restrictions on housing typology and no compulsory minimum space requirement per person. Maximum built up in a plot is controlled by FSI (Floor Space Index) that is based on adjoining road width, but there is no restriction on the lower limit (Pune Municipal Corporation 2018). Thus, the development controls let the influencing parameters take shape naturally and allow the manifestation of mixed land-uses.

For the validity of the macro-level mixed land-use predictive model, four neighbourhoods of varying character and location are taken for micro-level analysis. The results from the model developed in this study are compared with traditional indicators of mixed land-use intensity at the micro-level.

\section{Methods and Materials}

Parameters that are to be used for predicting mixed land-use were finalised through a two-hour Focused-Group-Discussion with experts. A total of 10 experts from the field of urban economics, urban planning, GIS application in urban planning and urban planning expert involved in development plan preparation participated in the Focused-GroupDiscussion. The aim of the study and context was presented to the gathered experts. The parameters from the literature listed in Table 1 were discussed in relation to how they influence mixed land-uses. The availability of robust data regarding the parameters and data processing were the critical concerns raised by the experts. In the end, the parameters finalised for macro analysis are connectivity, grain pattern, population density, and access to amenities. Location and layout are omitted as the macro analysis cover the entire city encompassing all locations and types of layouts. Weights used for the parameters in the further analysis was also decided in the same discussion.

\subsection{Mapping of Parameters}

Mapping and analysis are done in ArcGIS software version 10.2.2. Data regarding each parameter is converted into spatial information appropriately and georeferenced in Projected Coordinate System (WGS 1984 UTM Zone $45 \mathrm{~N}$ ). A total of 16 points was used for georeferencing. The process followed for data processing is explained further. The output raster cell size is 60 metres for all the parameters. Fig. 1 shows the maps of the parameters that influence mixed land uses.

Connectivity: There are higher chances of mixing uses in high road connectivity areas, as their accessibility is much more for a wider population (Shi \& Yang 2015). Commercial establishments would locate themselves along the major roads at the neighbourhood's edge due to higher accessibility and visibility rather than at the internal areas (Narvaez 2015). Distance from the major road is thus an influencing parameter for mixed land-use.

As per the development control regulations of Pune (Pune Municipal Corporation 2017), uses depend on the width of adjoining roads. Most nonresidential uses are allowed adjoining roads wider than 9 metres. Vector data of roads was extracted from Open Street Map (OSM) (OpenStreetMap ${ }^{\circledR}$ 2018). Roads wider than nine metres were retained and cross-checked with the Development Plan of Pune (Pune Municipal Corporation 2018). The en- 


\section{sciendo}

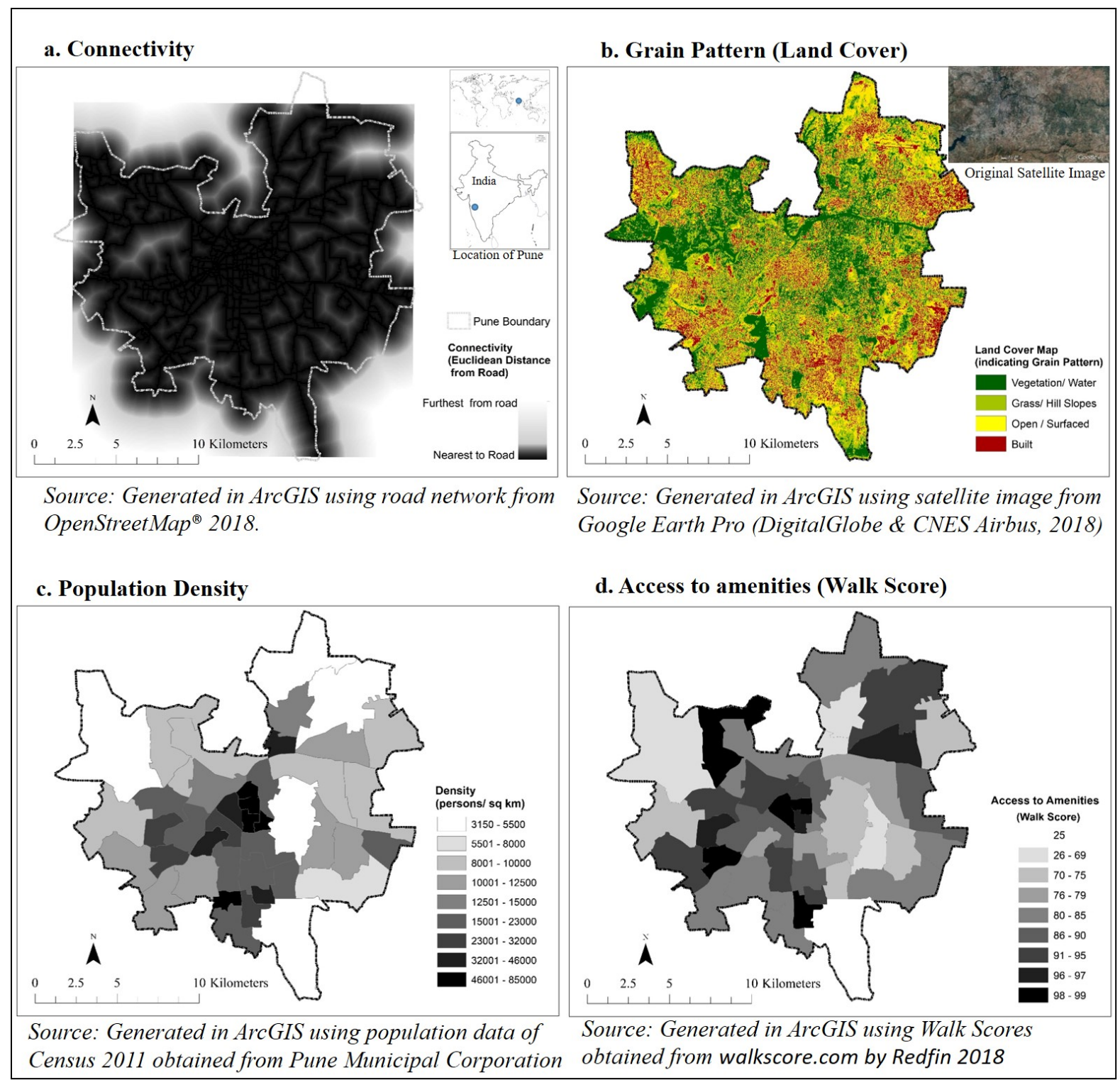

Fig. 1 Maps of mixed land-use influencing parameters

tire city of Pune is then scaled based on the connectivity of roads wider than nine meters using the 'Euclidian Distance tool' in ArcGIS. The Euclidean distance output raster contains the measured distance from every cell to the nearest source/road (ESRI 2018). Areas with shorter Euclidian Distances have a higher potential of mixed land-use development. The resultant is in the form of a raster map that is shown in Fig. 1a.

Grain Pattern: Grain pattern explains the mix and relationship between open and built environments, indicating the sizes of buildings, plots or blocks created by road networks (Jacobs, 1961; Lynch, 1984). When small land parcels dominate this pattern, it can be called fine-grain (Norton, 2015). For this study, interpretation of grain pattern is made from land cover information processed from a satellite image downloaded from Google Earth Pro (DigitalGlobe \& CNES Airbus 2018). As the visibility of buildings was necessary for interpreting grain pattern, higher resolution images of around $10 \mathrm{~m}$ per pixel available from Google Earth Pro is found to be the most appropriate and easily available source. A few trial analyses were carried out with satellite images from Bhuvan - Linear Imaging and Self Scanning Sensor (LISS), which has a resolution of 24 metres and from EarthExplorer - Landsat 8 Operational Land Imager, which has a resolution of 30 metres. Nevertheless, as buildings were not precisely distinguishable in them, the image from Google Earth Pro was chosen for further analysis. The main limitation arising was the absence 
of multispectral information which does not pose a substantial problem for this study. The landcover map is generated using the 'Iso-Cluster Unsupervised Classification Tool' in ArcGIS. Various other methods of generating land cover maps exist but given that the primary goal here was to distinguish the built-up area and there is no necessity for identifying vegetation or soil types, the isoclustering method fulfils the requirements (Oyekola \& Adewuyi 2018). The raster image of the land cover obtained is shown in Fig. 1 b.

Land cover is classified into four groups. Small but frequent buildings representing fine grains are given a higher value to indicate their influence in mixed land-use manifestation. Buildable but open or surfaced areas are given the next higher value. Around 45 per cent of the city's area is either under surfaced or built category. Unbuildable areas are least likely to host mixed land-use, and the land-cover map helps to eliminate those areas from the analysis. Around 55 per cent of the city's area is in this category. Unlike the rest of the parameters where a range is created between high and low values, the grain pattern is not classified into a range of fine to coarse grain, but built-up areas are extracted as grains. The grains represented by builtup help to break down the ward level data of other parameters and bring those attributes to build areas only.

Density: Higher population density promote higher activity levels, thereby becoming more attractive to residents as well as commercial establishments (Jacobs-Crisioni et al. 2014). Businesses also find the required threshold market for sustenance ((O'Sullivan 2012). The opposite is also true that commercial establishments may not have enough customers or threshold population to thrive in low-density areas. Population density of electoral wards of Pune is computed from population census 2011 data by dividing the population of each ward by its area (Pune Municipal Corporation 2020). As further analysis was to be performed on raster data sets, the electoral ward feature with the information in the density field was converted to a raster image using the 'Feature to Raster Conversion Tool' of ArcGIS. Thematic map of population density variation across the city as shown in Fig. $1 \mathrm{c}$ is made using 'Quantities - Graduated Colour' in 'Layer Properties - Symbology' with the approximate class sizes as per India's National Planning Guidelines (Mott MacDonald 2014).

Access to amenities and facilities: As mixed landuse for this study is understood as the extent of coexistence of residential and non-residential activities, the purpose of mixed land-use is from the per- spective of the residents. The main benefit of mixed land-use for residents is the access to various essential non-residential uses that is amenities and facilities like convenience shopping, health care etc. (Grant, 2002; Hirt, 2007). Hence, a measure that would represent access to amenities and facilities of the residents serves as an influencing parameter of mixed land-uses. Access to amenities is analysed based on Walk Scores computed by a website 'www.walkscore.com' (Redfin 2020). Walk Scores have been used in other researches as an indicator of access to amenities (Carr et al. 2011; Duncan et al. 2011). For each address, Walk Score analyses the walking routes to nearby amenities (amenities are determined from POIs in open access sources). Points are given based on the distance to pre-fixed amenities such as grocery, schools, parks, entertainment, dining etc. Amenities within a 5-minute walk (400 metres) get maximum points. A decay function is used to give points to farther located amenities, with no points given after a 30-minute walk (Redfin 2020). Walk Scores for five locations distributed spatially within each electoral ward of Pune are taken, and then the average is recorded as access to amenities score for an electoral ward. Similar to density, the electoral ward feature with the information in the Walk Score field is converted into a raster image using the 'Feature to Raster Conversion Tool' of ArcGIS. The thematic map of access to amenities is shown in Fig. 1d.

\subsection{GIS Modelling for Mixed Land-Use Visu- alisation at the Macro-Level}

'Weighted Overlay Analysis' enables multicriteria decisions by producing combined spatial information of the input layers based on the conditions set in the model (ESRI 2016a). The model used for the analysis is shown in Fig. 2.

The input raster images layers of the parameters connectivity, grain pattern, population density and access to amenities were all in different ranges and hence were reclassified. For instance, density ranged from the value 3000 to 80000 , whereas access to amenities ranged from values 24 to 99. Moreover, while higher densities would lead to a higher probability of mixed land-use, a smaller euclidean distance in connectivity leads to higher chances of mixed land-use. Through the 'Reclassify' tool, the data of all parameters were progressively ordered starting from ' 1 ', where the value ' 1 ' would represent the lowest probability of mixed land-use scenario and the increase in order value would represent the increased probability of mixed land-use. 


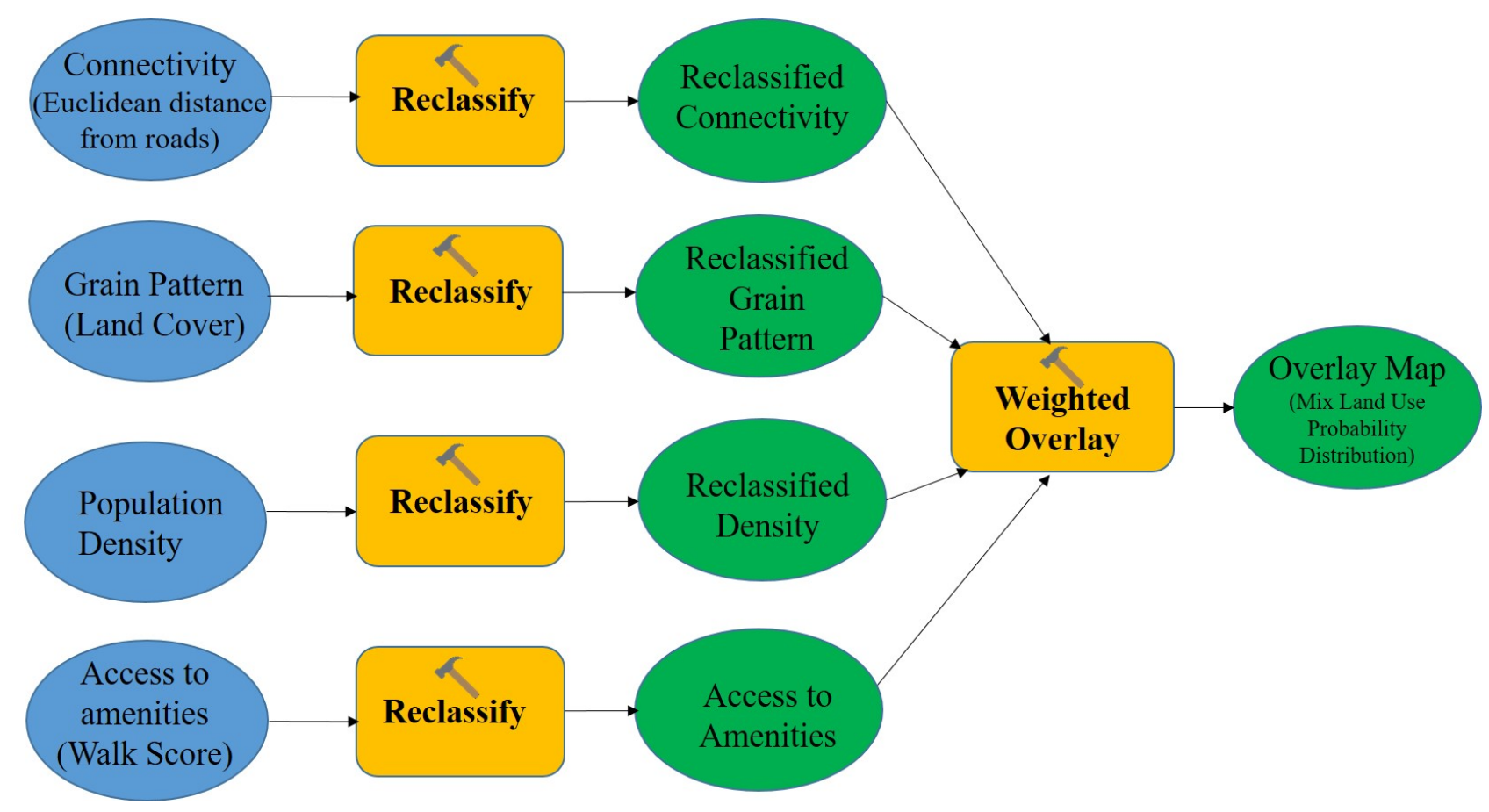

Fig. 2 ArcGIS Model for visualisation and of the mixed land-use intensity distribution at macro-level

The weights for the parameters used in the weighted overlay tool was decided through the expert's focus-group discussion. Connectivity, density and access to amenities were all given a weightage of 20 per cent, and grain pattern was given a weightage of 40 per cent. As all information was to be reflected at the scale of building footprint in grain pattern, higher weight was given to it.

An evaluation scale of 1 to 9 was used in the model. These act as weights for the ordered values in the reclassified layers representing parameters. For instance, the order in density varied from 1 to 40 and that of access to amenities varied from 1 to 23 . They were classified into 1 to 9, as indicated in Fig 1. For the grain pattern parameter, the values ranged only from 1 to 4 . As value ' 4 ' represent built parcels, it was given the weight of ' 9 ', value ' 3 ' represent surfaced parcels, and it was given the weight of ' 6 '. As values ' 1 ' and ' 2 ' represent the unbuildable area, there is a low probability of mixed land-use occurrence there, and they were given a weight of ' 1 '. The resultant overlay map scales the entire city in categories of mixed land-use probability. The resolution of the output raster is 60 metres. The actual area under each mixed land-use probability level is obtained by the Spatial Analyst tool 'Zonal Geometry as Table' in ArcGIS (ESRI 2016b). It can be used to predict the mixed land-use intensities for neighbourhoods throughout the city.

\subsection{Validation of Macro-Level Mixed land- use Intensity Prediction Model through Micro-Level Comparison}

The results obtained from the macro-level analysis in the form of an overlay map/mixed land-use probability map as shown in Fig. 3 that visualises and predicts the distribution of mixed land-use is validated through micro-level analysis. Four neighbourhoods of different physical characters in terms of density, age, housing and planning history across the city are selected. The raster image of the mixed land-use probability map from the macro analysis is clipped to the boundaries of the neighbourhoods using 'Clip (Data Management Tool)' in ArcGIS. As the mixed land-use probability map has a progressive classification level, the number of pixels under each such level is obtained during the clipping of the image. Areas under each mixed land-use probability level are obtained using the same 'Zonal Geometry as Table Tool'. The proportion of areas under each mixed land-use probability level is used to compare different areas as they can vary in size. Values associated with the mixed land-use probability levels are used as weights for computing a weighted sum that would indicate a mixed land-use intensity prediction of a neighbourhood as shown in equation 1.

$$
M=\sum_{i=1}^{n} i \cdot P_{i}
$$




\section{sciendo}

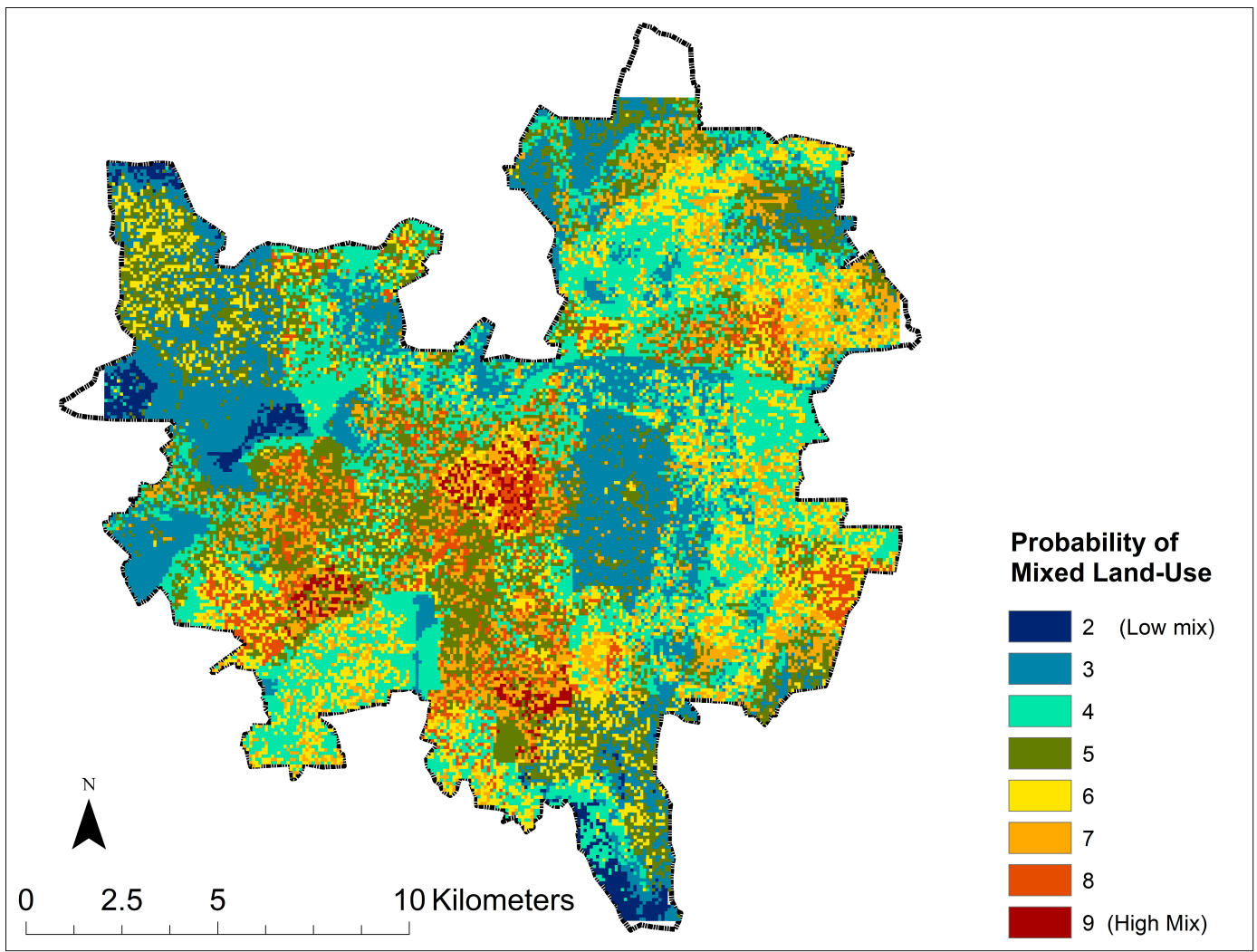

Fig. 3 Result of Weighted Overlay Analysis (Mixed land-use probability distribution at macro-level)

where $M=$ mixed land-use intensity prediction of a neighbourhood, $n=$ number of levels of mixed land-use probability, $i=$ numeric value associated with each mixed land-use probability level, $\mathrm{Pi}=$ proportion of area covered under each mixed land-use probability level $i$ (calculated by area under pixels representing the level).

As the maximum possible weight is ' 9 ' and the maximum proportion of the area is ' 1 ', the mixed landuse intensity prediction is out of ' 9 '. This predicted indicator of mixed land-use is compared with wellestablished mixed land-use indicators or real indicators for neighbourhoods computed from real landuse distribution.

Land-uses data for each land parcel/ plot was documented through a primary survey of the selected neighbourhoods. The land parcel boundaries from the development plan are used in the base map for documenting the land-use. The land-use of each parcel was marked on the prints of the map during the neighbourhood visit and then later digitised in GIS. Photographs and videos were also recorded for future reference. Areas under each land-use category are computed in ArcGIS using 'Calculate Geometry' in the attributes table of the neighbourhood's land-uses. In Pune City, especially in the old/core area of the city, there is a high prevalence of vertical mixed-use. All such plots are categorised as mixed-use plots. The proportion of the area of the neighbourhood under this vertical mixed-use is taken as an indicator of mixed land-use intensity for neighbourhoods. Herfindahl-Hirschman Index captures the proportion and distribution of different land-use in a neighbourhood, and it is taken as another indicator (Manaugh \& Kreider 2013; Song et al. 2013). It is computed as the sum of squares of the percentage share of different land-uses in the neighbourhood. If only one land-use is present (for example, there is 100 per cent residential use), the index for such a scenario will be '1002' i.e. '10000'. An additional type of land-uses would create a lesser share of area under one particular land-use, and therefore index will be smaller (for example, 50 per cent commercial and 50 per cent residential will be $502+502=5000$ ). The different land-use categories considered are residential, commercial, recreational (parks and gardens), public/semipublic/institutional, services/utilities, industrial, religious and vacant. However, as the Herfindahl-Hirschman Index does not give due consideration to vertical mixed-use, the first in- 


\section{sciendo}

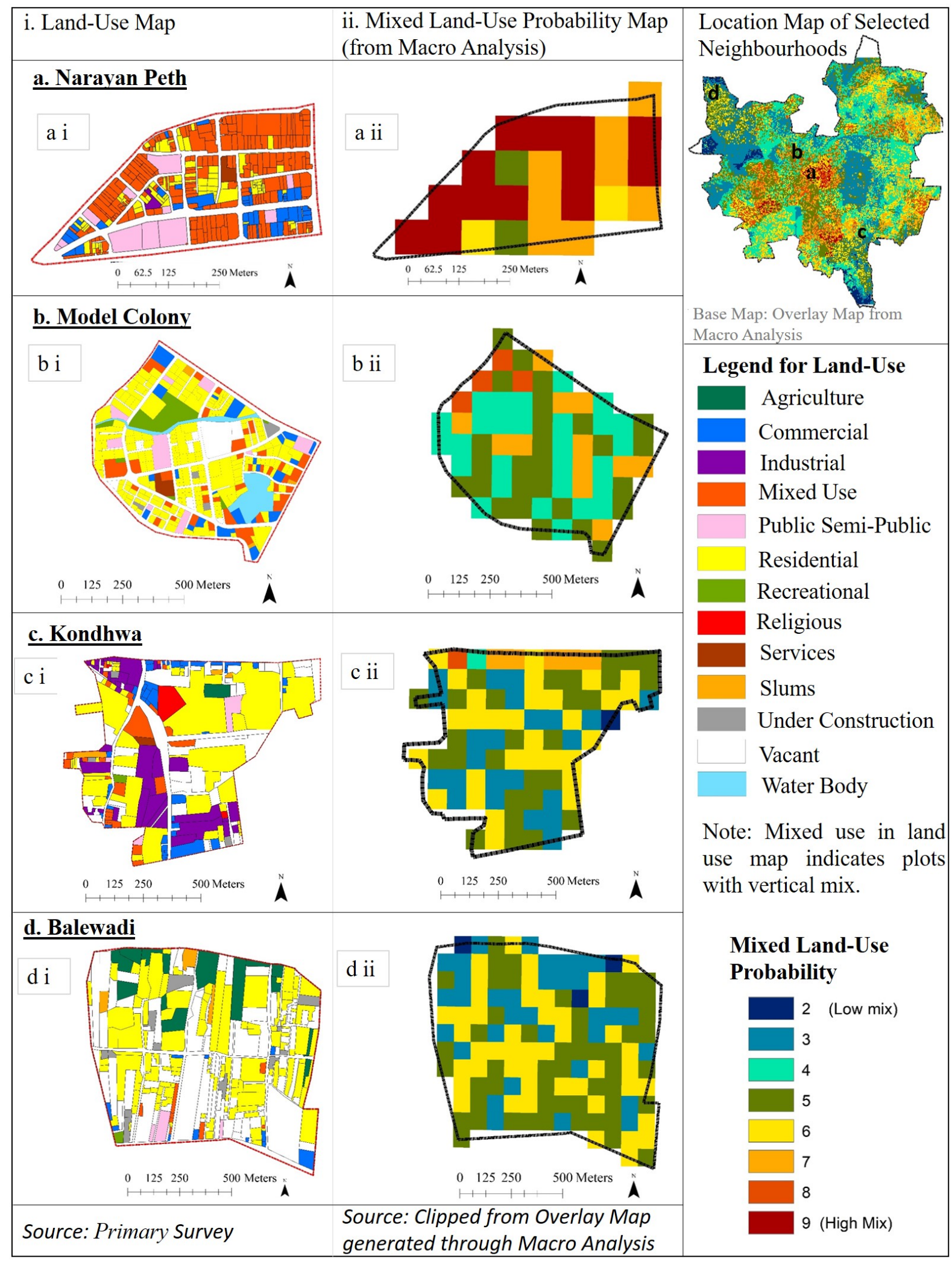

Fig. 4 Land use maps and clips from overlay map of selected neighbourhoods 
dicator of the proportion of area under vertical mix in the neighbourhood is simultaneously considered. The four neighbourhoods are then ranked based on these indicators for comparison, and conclusions are drawn.

\section{Results and Discussion}

The resultant map of the Weighted Overlay Analysis is shown in Fig. 3. While each parameter influences the probability of mixed land-use, the output of the model gives a combined prediction.

The entire city is categorised into eight levels varying from value ' 2 ' representing low mixed landuse probability to value ' 9 ' representing high mixed land-use probability. It can be understood as pixels with value ' 9 ' have a $9 / 9$, i.e. 1 or 100 per cent probability of mixed land-use; pixels with value 3 have a $2 / 9$, i.e. 0.22 or 22 per cent probability of mixed land-use. There are no pixels with the value ' 1 ' as none of the areas had a scenario of weight ' 1 ' of all parameters. As a higher weight was used for grain pattern with the highest weight for built areas, the pixels corresponding to buildings are easily distinguishable from their surroundings. Even in areas where connectivity, density and access to amenities are low, the pixels corresponding to buildings indicate a comparatively higher probability of mixed land-use. The lower probability values of ' 2 ', ' 3 ', and ' 4 ' are indicative of areas that are not built yet, but their order still indicates the probability of mix land-use presence based on other parameters. About 46 per cent of the city area falls under one of these three categories with a mixed landuse probability of $4 / 9$, i.e. 0.44 or lesser. For these areas, the probabilities can be seen from a future perspective. Pixels with the value ' 5 ' may include areas with very low intensity built-up. About 19 per cent of the city area is in this category with a mixed land-use probability of $5 / 9$, i.e. 0.56 . Pixels with values from ' 6 ' to ' 9 ' show variations in the probability of mixed land-use in existing built areas. Around 35 per cent of the city area has a 6/9 i.e. 0.67 or more probability of mixed land-use.

Fig 4 indicates the real land-uses of the sample neighbourhoods as well as the mixed land-use probability map that is clipped from the results of the macro analysis. Table 2 indicates the results of the computation of mixed land-use indicators from real land-use data as well as from the clipped data of the macro-level results for selected neighbourhoods.

The real mixed land-use indicators confirm with the mixed land-use intensity prediction computed from the results of the macro analysis model (mixed land-use probability map). The ranks of the neighbourhoods predicted from the model are the same as the ranks as per the real indicators.

Neighbourhood ' $a$ ', Narayan Peth, is one of the oldest neighbourhood in Pune, with almost 60 per cent of its area under vertical mixed-use. It also has the smallest value for the Herfindahl-Hirschman Index, indicating that it has the maximum prevalence of mixed land-use amongst the selected neighbourhoods. In the modelled mixed land-use probability map, Narayan Peth has maximum pixels with value ' 8 ' and ' 9 ' and none of the pixels with a value below ' 5 '. The model, therefore, correctly predicted the mixed land-use intensity for neighbourhood ' $a$ '. Neighbourhood ' $b$ ', Model Colony, is a planned neighbourhood with plotted development but does have substantial non-residential uses. As per the real indicators, the prevalence of mixed landuse in neighbourhood ' $b$ ' is not as much as neighbourhood ' $a$ ', but it can be called a fairly mixeduse neighbourhood. In the modelled mixed land-use probability map, Model Colony has maximum pixels with value ' 4 ' ' and ' 5 ' representing low-intensity built-up areas. But it also has few pixels with value ' 8 ' and ' 9 ', indicating the presence of high mixed land-use intensity in pockets. Thus, the predicted mixed land-use intensity in neighbourhood ' $b$ ' is in agreement with the real indicators.

Neighbourhood ' $c$ ', Kondhwa has low population density and access to amenities. This is partly due to the prevalence of industrial estates in the neighbourhood. However, it does have intense built-up areas in pockets as well as vacant lands. For the real indicators, the variety of land-uses in Kondhwa is more than the other neighbourhoods. But they are in clusters and not uniformly distributed. Moreover, the prevalence of vertical mixed-use is much lower, placing this neighbourhood ' $c$ ' after neighbourhood ' $a$ ' and ' $b$ ' for intensities of mixed landuse. As per the modelled mixed land-use probability map, there are only a few pixels with value ' 7 ' or greater but have almost equal shares of pixels with value ' 3 ', ' 5 ' or ' 6 '. Even if there are more levels of mixed land-use probability in neighbourhood ' $\mathrm{C}$ ', the variation is mostly in the middle values resulting in it being placed third in the ranking, similar to the real indicator results.

Neighbourhood ' $d$ ', Balewadi, is the newest neighbourhood in consideration and has a substantial number of vacant plots. It is therefore placed last for mixed land-use intensity among the studied neighbourhoods according to the real indicators. In the modelled mixed land-use probability map, none of the pixels has a value more than ' 5 ', 
Table 2 Validation of model through comparison of results with established mixed land-use indicators

\begin{tabular}{|c|c|c|c|c|c|c|c|}
\hline Code & $\begin{array}{l}\text { Neighbourhood } \\
\text { Name }\end{array}$ & $\begin{array}{l}\text { The proportion } \\
\text { of area under } \\
\text { mixed-use }\end{array}$ & $\begin{array}{l}\text { Herfindahl } \\
\text {-Hirschman } \\
\text { Index }\end{array}$ & $\begin{array}{l}\text { Mixed land-use } \\
\text { intensity prediction } \\
\text { from model }\end{array}$ & $\begin{array}{l}\text { Rank as per } \\
\text { the proportion } \\
\text { of area under } \\
\text { mixed-use }\end{array}$ & $\begin{array}{l}\text { Rank as per } \\
\text { Herfindahl } \\
\text {-Hirschman } \\
\text { Index }\end{array}$ & $\begin{array}{l}\text { Rank as per } \\
\text { model prediction }\end{array}$ \\
\hline $\mathrm{a}$ & Narayan Peth & 0.6 & 1234 & 7.87 & 1 & 1 & 1 \\
\hline $\mathrm{b}$ & Model Colony & 0.13 & 3882 & 5.07 & 2 & 2 & 2 \\
\hline c & Kondhwa & 0.08 & 4165 & 4.91 & 3 & 3 & 3 \\
\hline $\mathrm{d}$ & Balewadi & 0.02 & 7823 & 4.78 & 4 & 4 & 4 \\
\hline
\end{tabular}

and almost one-third of the pixels have a value of ' 3 ' or ' 2 '. Thus the mixed land-use intensity prediction for neighbourhood ' $d$ ' is a low mix, matching with the results of real indicators.

However, despite the fair accuracy in predicting mixed land-use intensities of neighbourhoods, the model results do not always correctly predict mixed land-use presence for each land parcel. If it is observed that a particular plot has vertical mixeduse, it is not necessary that in the predicted mixed land-use map it would have a probability value of ' 9 '. The reason for the anomaly is due to the resolution of data considered for overlay analysis. The density and access to amenities score used for overlay analysis were averaged values applicable to large areas. The distinction seen at the pixel level is mostly due to grain pattern.

\section{Conclusions}

This research establishes a GIS-based model to visualise and predict the mixed land-use distribution in terms of probability of mixed land-use across a city using spatial data of parameters that influence mixed land-uses. The model does not depend upon parcel-level land-use or other detailed spatial information. A combination of the influencing parameters, namely connectivity, population density, grain pattern and access to amenities, can successfully predict mixed land-use distribution. Based on the literature, it was assumed that all the selected parameters are co-related with mixed landuse. The spatial information of all the parameters is suitably pre-processed into raster images. The model developed used these raster images of influencing parameters as input layers, reclassified them into progressive orders before amalgamation through Weighted Overlay Analysis.

The resultant overlay map scales the entire city into eight progressive categories of the mixed land-use ranging from low mix to high mix. About 35 per cent of Pune city has 0.67 or more probability of mixed land-use, 19 per cent of the city area has 0.56 probability, and 46 per cent of the city area has a 0.44 or lesser probability of mixed land-use.

The predicted mixed land-use distribution produced through overlay analysis at the macro-level can be used to compute mixed land-use intensity for neighbourhoods in the city. The order of probability of mixed land-use is multiplied with the area under each order in a neighbourhood and added to get an indicator for mixed land-use intensity. The predicted indicator for four sample neighbourhoods is validated by comparing with the traditional indicators computed from real land-use information. Validation of the model further established the colinear relationship of the influencing parameters with mixed land-use.

One of the limitations of this study is that the prediction could not correctly predict the mixed landuse scenario for each land parcel as the data used for some of the parameters were for broader areas. Also, data regarding the influencing parameters are not from the same year, which could have affected the results. Euclidean Distance Analysis tool in GIS omitted certain parts (towards the edge), and those parts could not be included, which is another limitation of the study. Output cell resolution of 60 metres was used due to system restrictions. The methodology established in this research can be used for higher resolution output, same as the resolution of the satellite image used as an input.

The findings of this research are useful in the area of urban land-use. It could serve as a starting point for the decision-making process regarding mixed land-use policies. Any study that intends to measure the effects of mixed land-use can make use of the results of the study. The results could also assist real estate developers in deciding whether their project should be residential or a mix of residential and commercial, depending on the location and the associated mixed land use probability. The model developed to predict mixed land use distribution is most useful for cities where land-use data is not available. The model is applicable to cities with lax developmental regula- 
tions allowing for mixed land-use to develop under the influence of various other urban parameters. There are other researches that have shown that these urban parameters like density and connectivity do have a relationship with mixed landuses in Asian and European cities. Hence the model and the mixed land-use measurement techniques would be valid even for international cities. The future scope based on this research is including parcel-level land-use data in the model when available and testing the applicability of the model in various other contexts. It will be interesting to see how the effect of the influencing parameters compares in cities around the globe.

\section{Declaration}

The authors declare no conflict of interest. No funding has been received for this work.

\section{References}

Abdullahi S, Pradhan B, Mansor S, Shariff ARM (2015) GIS-based modeling for the spatial measurement and evaluation of mixed land use development for a compact city. GIScience \& Remote Sensing 52(1): 18-39.

Ahluwalia IJ (2019) Indian cities need a new planning template. Available from: <https://www.financialexpress.com/opinion/indian-cities-need-a-new-planning-templateheres-why/1661159>

Bahadure S, Kotharkar R (2015) Assessing sustainability of mixed use neighbourhoods through residents' travel behaviour and perception: The case of Nagpur India. Sustainability 7 : 12164-12189.

Bordoloi R, Mote A, PratimSarkar P, Mallikarjuna C (2013) Quantification of land use diversity in the context of mixed land use. s.l. Procedia - Social and Behavioral Sciences 104: 563-572.

BusinessLine (2012) Majority of cities yet to develop master plan. Available from: <https://www.thehindubusinessline.com/news/majority-of-cities-yet-to-develop-masterplan/article23084739.ece>

Carr LJ, Dunsiger SI, Marcus BH (2011) Validation of Walk Score for estimating access to walkable amenities. British Journal of Sports Medicine 45(14): 1144-1148.

Chen L (2014) Redefining the typology of landuse in the age of big data, Massachusetts Institute of Technology, Cambridge.

Diddee J, Gupta S (2013) Pune queen of the Deccan. Elephant Design Pvt. Ltd., Pune.

DigitalGlobe \& CNES Airbus (2018) Satellite image of Pune. Google Earth Pro.

Duncan DT, Aldstadt J, Whalen J, Melly SJ, Gortmaker SL (2011) Validation of Walk Score ${ }^{\circledR}$ for estimating neighborhood walkability: An analysis of four US metropolitan areas. International Journal of Environmental Research and Public Health 8(11): 4160-4179.
ESRI (2016a) ArcGIS for Desktop- ArcMap - How Weighted Overlay works. Available from: < https://desktop.arcgis.com/en/arcmap/10.3/tools/spatial-analyst-toolbox/how-weighted-overlayworks.htm>

ESRI (2016b) Zonal geometry as table. Available from: $<$ https://desktop.arcgis.com/en/arcmap/10.3/tools/spatialanalyst-toolbox/zonal-geometry-as-table.htm>

ESRI (2018) Understanding euclidean distance analysis. Available from: <https://pro.arcgis.com/en/pro-app/toolreference/spatial-analyst/understanding-euclidean-distanceanalysis.htm>

Gehrke SR, Clifton KJ (2016) Toward a spatial-temporal measure of land-use mix. The Journal of Transportation and Land Use 9(1): 171-186.

Gervasoni L, Bosch M, Fenet S, Sturm P (2016) A framework for evaluating urban land use mix from crowd-sourcing data. 2nd International Workshop on Big Data for Sustainable Development, Washington DC, United States. IEEE: 2147-2156.

Grant J (2002) Mixed use in theory and practice: Canadian experience with implementing a planning principle. Journal of the American Planning Association 68(1): 71-84.

Herndon JD, Drummond W (2011) Mixed-Use development in theory and practice: Learning from Atlanta's mixed experiences. Available from: <https://smartech.gatech.edu/bitstream/handle/1853/40790/JoshuaHerndon_Mixed-Use\%20Development\%20in\%20Theory\%20and\%20Practice.pdf>

Hirt S (2007) The Mixed-use Trend: Planning attitudes and practices in Northeast Ohio. Journal of Architectural and Planning Research 24(3): 224-244.

Hoek JW van den (2008) The MXI (Mixed-use Index) an instrument for anti sprawl policy?. In: 44th ISOCARP Congress, Dalian, China.

Hoppenbrouwer E, Louw E (2005) Mixed-use development: Theory and practice in Amsterdam's Eastern Docklands. European Planning Studies 13(7): 967-983.

Huang S-W, Tsai W-J (2013) The analysis of measurements and influence factors of mixed land use. International Journal of Bioscience, Biochemistry and Bioinformatics 3(3): 206-210.

Jacobs-Crisioni C, Rietveld P, Koomen E, Tranos E (2014) Evaluating the impact of land-use density and mix on spatiotemporal urban activity patterns: An exploratory study using mobile phone data. Environment and Planning A: Economy and Space 46(11): $2769-2785$

Jacobs J (1961) The death and life of great American cities. Random House, New York.

Kajtazi B (2007) Measuring multifunctionality of urban areas, ITC, Netherlands. Available at: <https://webapps.itc.utwente.nl/librarywww/papers_2007/msc/upla/kajtazi.pdf>

Kawabe A, Watanabe S (2018) An analysis of mixed land use towards designing the compact city. In: 23rd International Conference of the Association for Computer-Aided Architectural Design Research in Asia (CAADRIA), Hong Kong, 2: 493-502.

Lynch K (1984) Theory of Good City Form. MIT Press, Cambridge, Massachusetts, United States.

Manaugh K, Kreider T (2013) What is mixed use? Presenting an interaction method for measuring land use mix. The Journal of Transport and Landuse, 6(1): 63-72.

Mashhoodi B, Pont MB (2011) Studying land-use distribution and mixed-use patterns in relation to density accessibility and urban form. 18th International Seminar on Urban Form: Urban Morphology and the Post-Carbon City. Montreal, Canada. 


\section{S sciendo}

Ministry of Housing and Urban Affairs (2016) Smart city features. Available from: <http://smartcities.gov.in/content/innerpage/smart-city-features.php>

Ministry of Housing and Urban Affairs (2017) National Transit Oriented Development (TOD) Policy, Government of India. Available from: < https://smartnet.niua.org/content/4d80e2fffab5-4434-9e3c-53f227a8b575>

Moreri KK (2020) Using Kappa methodology to consider volunteered geographic information in official land administration systems in developing countries. Spatial Information Research 28 299-311.

Mott MacDonald (2014) Urban and Regional Development Plans Formulation and Implementation (URDPFI) Guidelines, Ministry of Housing and Urban Affairs, Government of India, New Delhi.

Narvaez L (2015) The morphology of mixed uses. Future of Places Conference, UN-HABITAT, Projects for Public Spaces. Stockholm, Sweden.

Norton CA (2015) The role of fine urban grain in securing the diversity of the urban centre, University of the West of England, Bristol.

O’Sullivan A (2012) Urban economics. McGraw Hill, New York.

OpenStreetMap ${ }^{\circledR}$ (2018) Available from: <https://www.openstreetmap.org/copyright>

Oyekola MA, Adewuyi GK (2018) Unsupervised classification in land cover types using remote sensing and GIS Techniques. International Journal of Science and Engineering Investigations 7(72): $11-18$.

Pune Municipal Corporation (2017) Development Control and Promotion Regulations, Pune.

Pune Municipal Corporation (2018) Development Plans. Available from: <https://pmc.gov.in/en/draft-development-plan-oldpmc-limit-2007-2027-published-us-311-mrtp-act-1966>

Pune Municipal Corporation (2020) Census data. Available from: <https://pmc.gov.in/en/census>
Raju P (2003) Spatial Data Analysis. In: Proceedings of workshop: Satellite remote sensing and GIS applications in agricultural meteorology, Dehra Dun, India, pp. 151-174.

Raman R, Roy UK (2019) Taxonomy of urban mixed land use planning. Land Use Policy 88: 104102.

Redfin (2020) Walk Score. (Data provided by Redfin Real Estate) Available from: <https://www.walkscore.com/score/>

Rodenburg C, Nijkamp P (2004) Multifunctional landuse in the city: A typological overview. Built Environment 30(4): 274-288.

Rowley A (1996) Mixed-use Development: Ambiguous concept, simplistic analysis and wishful thinking?. Planning Practice \& Research, 11(1): 85-98.

Shi B, Yang J (2015) Scale, distribution, and pattern of mixed land use in central districts: A case study of Nanjing, China. Habitat International 46: 166-177.

Song Y, Merlin L, Rodriguez D (2013) Comparing measures of urban land use mix. Computers, Environment and Urban Systems 42: $1-13$.

Williams K. (2004) Can urban intensification contribute to sustainable cities? An international perspective. City Matters. Available from: < https://www.semanticscholar.org/paper/Can-urban-intensification-contribute-to-sustainableWilliams/6da8a1c80cffef60e645053d3f9cc122303bf06d>

Yinan Z (2009) Intensity control in mixed-used new urban area: a case study of the waterfront in Xiasha, Hangzhou. The New Urban Question - Urbanism beyond Neo-Liberalism, The 4th International Conference of the International Forum on Urbanism (IFoU), Amsterdam: 1395-1404.

Yue Y, Zhuang Y, Yeh AG, Xie JY, Ma CL, Li QQ (2017) Measurements of POI-based mixed use and their relationships with neighbourhood vibrancy. International Journal of Geographical Information Science 31(4): 658-675.

Zagorskas J (2016) GIS-based modelling and estimation of land use mix in urban environment. International Journal of Environmental Science 1: 284-293. 